\title{
Visualizing Zinc Dendrites in Minimal Architecture Zinc Bromine Batteries via in-house Transmission X-ray Microscopy
}

Jeung Hun Park ${ }^{1}$, Daniel Steingart ${ }^{2}$ and Bruce Koel ${ }^{1}$

${ }^{1}$ Princeton University, Princeton, New Jersey, United States, ${ }^{2}$ Columbia University, New York, New York, United States

*Corresponding Authors: Prof. D. A. Steingart (dan.steingart@columbia.edu), Prof. B. E. Koel (bkoel@princeton.edu)

Development of low-cost $(\$ 100 / \mathrm{kWh})$, long-cycle life $(>10,000)$ electrochemical energy storage devices or batteries is necessary for the transition toward the future of renewable energy [1]. The electrochemical performance of batteries can be compromised by the formation of metal dendrites during cycling processes [2]. Organic chemical additives in the electrolytes represent a useful strategy to mitigate dendrite formation, but a fuller understanding requires knowledge of the morphological effects of chemical additives during the cycling process [2,3]. Such information would also aid in developing new strategies for additive design for optimized cycling performance. Traditional ex situ microscopy has been used extensively for studying energy materials and devices to obtain spatial and chemical information, but analysis requires disassembling materials from their native environments [4]. In situ liquid cell transmission electron microscopy (TEM) enables obtaining more representative information that would otherwise be missing or misleading [5]. However, the experimental conditions for specialized probing systems with modified battery structures may result in significant deviation from normal operating conditions of commercial batteries (e.g. use of an ionic liquid or dry cell setup in TEM) [4]. Alternatively, in situ transmission X-ray microscopy (TXM) can provide three-dimensional (3D) morphological and chemical information on batteries in realistic operating conditions $[4,6]$. In this work, we utilized an inhouse TXM instrument to visualize the 3D growth morphology of zinc dendrites on carbon cloth electrodes during cycling in electrolytes containing organic additives within minimal architecture zinc bromine batteries (MA-ZBBs). Zinc bromide chemistry has already demonstrated a potential opportunity for future energy storage solutions with long cycle life $(>10,000)$ and low operating cost $(\$ 10 / \mathrm{kWh})$ [7]. The experiments were carried out in a Carl Zeiss Xradia 520 Versa TXM to obtain X-ray 2D radiography and 3D tomography of MA-ZBBs. A home-built MA-ZBB was oriented vertically and only includes a carbon cloth anode, carbon foam electrode, and a zinc bromine electrolyte in a glass or Teflon ${ }^{\circledR}$ case. The MA-ZBBs (40 mAh, 1 hour storage) were cycled using various organic additive-embedded supporting electrolytes (Fig. 1). X-ray images were recorded in situ before and after cycling to investigate microstructural evolution and dendrite formation in the electrodes. 3D tomography data was used to examine the size distribution of dendrites and pores, and crack propagation. Metallic zinc is plated onto the anode during the charging process but is controlled via both chemical and electrochemical processes [8]. Zinc dendrites will not begin to grow until a critical cell potential is reached. The onset of dendrite formation is dependent on the local current density and concentration of electrolytes (Fig. 2). Dendrites form on surface inhomogeneities where the local current density is high and proceed to grow with various lengths. In Fig. 1 each gray spot corresponds to the formation site of $\mathrm{Zn}$ dendrite on the carbon cloth electrode. As zinc deposition proceeds, dendrites appear at various locations of the carbon cloth electrode. The height of dendrite trunks and number of dendrite branches clearly decreases with the use of organic 
chemical additives. Once dendrites are formed, a side reaction results in hydrogen evolution that can be suppressed by the organic chemical additives. We further discuss how such experiments can provide mechanistic insights into the inhibition of metal dendrite formation, which may be useful in energy materials and storage design. In summary, we used an in-house TXM as an efficient tool for imaging the internal structure of zinc dendrites within MA-ZBBs, demonstrating that X-ray microscopy can be useful to obtain mechanistic insights about organic chemical additives in new battery architectures. In the future we plan to examine multi-length scale 3D investigations of MA-ZBBs using electrochemical acoustic time of flight $(\mathrm{EAToF})$ and electrochemical impedance spectroscopy (EIS) to conduct in operando TXM/EAToF/EIS measurements. We are very thankful to Mr. Koshu Takatsuji for his helps in the fabrication and test of MA-ZBB cells. This material is based upon work supported by the National Science Foundation under Grant No. CHE-1800376. We also acknowledge the use of Princeton's Imaging and Analysis Center, which is partially supported through the Princeton Center for Complex Materials (PCCM), a National Science Foundation (NSF)-MRSEC program (DMR-2011750).

\begin{tabular}{|c|c|c|c|c|c|}
\hline Name & $\begin{array}{c}\text { CMC in } \\
\mathrm{H}_{2} \mathrm{O}(\mathrm{ppm})\end{array}$ & $\begin{array}{l}\text { Surface Tension } \\
\text { at } \mathrm{CMC}(\mathrm{mN} / \mathrm{m})\end{array}$ & Type & Structure & $\begin{array}{c}\text { Mw } \\
(\mathrm{g} / \mathrm{mol})\end{array}$ \\
\hline $\begin{array}{c}\text { Poly Ethylene } \\
\text { Glycol (PEG) } \\
600\end{array}$ & N/A & $50-70$ & Nonionic & & 600 \\
\hline $\begin{array}{c}\text { Sodium } \\
\text { Dodecyl } \\
\text { Sulfate (SDS) }\end{array}$ & 2450 & 39.5 & Anionic & & 288.4 \\
\hline $\begin{array}{c}\text { Triton-X } \\
100\end{array}$ & 140 & 31 & Nonionic & & 625 \\
\hline
\end{tabular}

Figure 1. Organic chemical additives contained in zinc bromide electrolytes. 

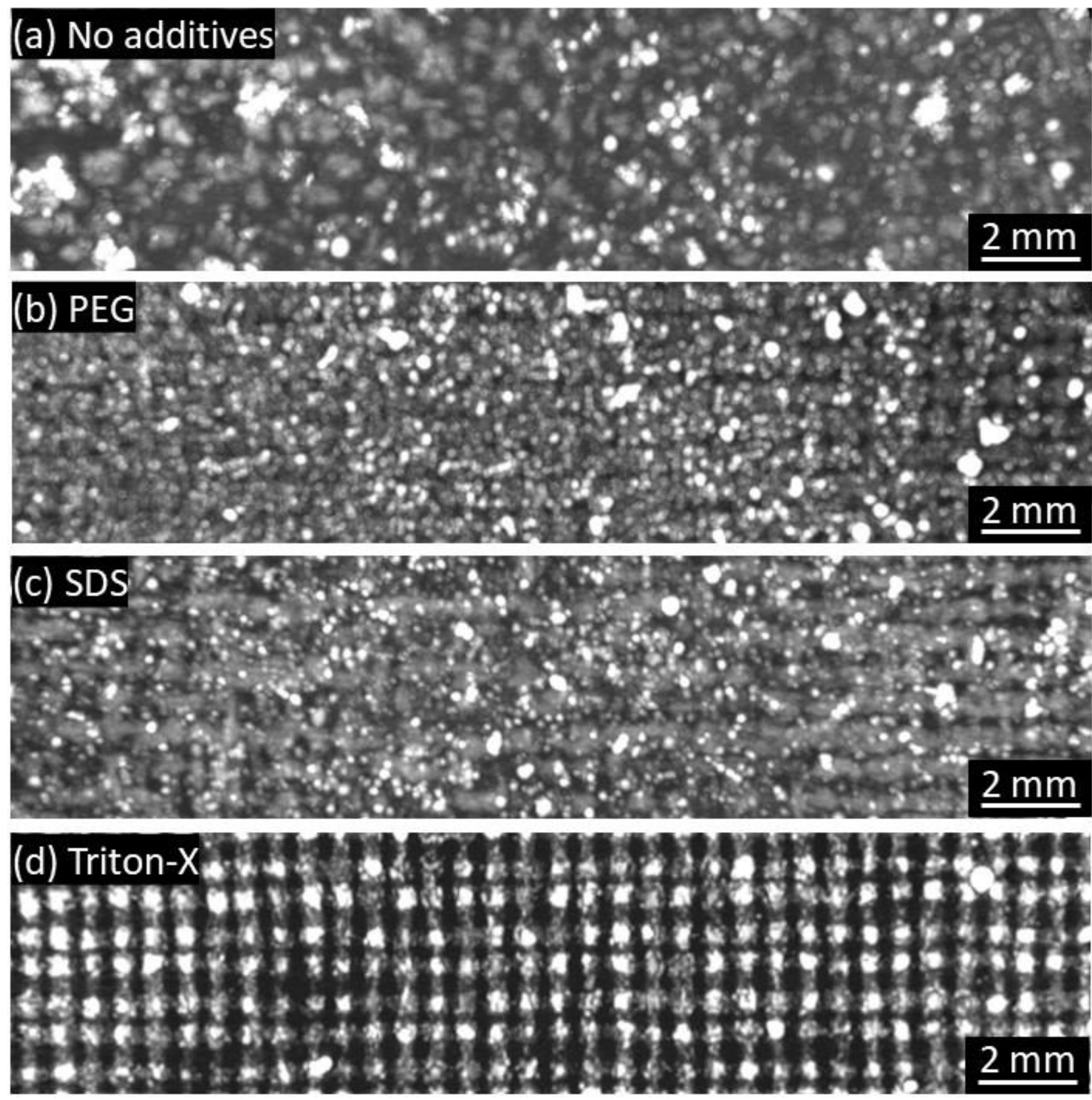

Figure 2. Top view of reconstructed TXM images of zinc dendrites on carbon cloth electrodes immersed in (a) additive-free, (b) polyethylene glycol 600, (c) sodium dodecyl sulfate, and (d) Triton-X 100 containing electrolytes during cycling of minimally architected $\mathrm{Zn}-\mathrm{Br}$ batteries.

References

[1] M. Skyllas-Kazacos, M. H. Chakrabarti, S. A. Hajimolana, F. S. Mjalli and M. Saleem, Journal of The Electrochemical Society 158 (2011), R55.

[2] Q. Yang, Q. Li, D. Wang, Y. Guo, X. Li, Y. Tang, H. Li, B. Dong, and C. Zhi, Advanced Materials 32 (2020) 2001854. 
[3] K. E. K. Sun, T. K. A. Hoang, T. N. L. Doan, Y. Yu, X. Zhu, Y. Tian, and P. Chen, ACS Applied Materials \& Interfaces 9 (2017) 9681.

[4] Y. Wu and N. Liu, Chem 4 (2018), 438.

[5] J. H. Park, N. M. Schneider, D. A. Steingart, H. Deligianni, S. Kodambaka, and F. M. Ross, Nano Letters 18 (2018), 1093.

[6] W. Chang, R. Mohr, A. Kim, A. Raj, G. Davies, K. Denner, J. H. Park, and D. A. Steingart, Journal of Materials Chemistry A 8 (2020) 16624.

[7] S. Biswas, A. Senju, R. Mohr, T. Hodson, N. Karthikeyan, K. W. Knehr, A. G. Hsieh, X. Yang, B. E. Koel, D. A. Steingart, Energy \& Environmental Science 10 (2017), 114.

[8] V. Yufit, F. Tariq, D. S. Eastwood, M. Biton, B. Wu, P. D. Lee, N. P. Brandon, Joule 3 (2019) 485. 